\title{
Toxoplasmic Lymphadenitis of the Head and Neck Region
}

\author{
Inn Chul Nam, Young Jin Cho, Beom Cho Jun, and Kwang Jae Cho \\ Department of Otolaryngology-Head and Neck Surgery, College of Medicine, The Catholic University of Korea, Seoul, Korea
}

\author{
두경부 영역의 톡소플라즈마성 림프절염 \\ 남인철 · 조영진 · 전범조 · 조광재 \\ 가톨릭대학교 의과대학 이비인후과학교실
}

\author{
Received January 3, 2014 \\ Revised February 4, 2014 \\ Accepted February 6, 2014 \\ Address for correspondence \\ Kwang Jae Cho, MD \\ Department of Otolaryngology- \\ Head and Neck Surgery, \\ The Catholic University of Korea, \\ Uijeongbu St. Mary's Hospital, \\ 271 Cheonbo-ro, \\ Uijeongbu 480-717, Korea \\ Tel $+82-31-820-3797$ \\ Fax $+82-31-847-0038$ \\ E-mail entckj@catholic.ac.kr
}

Toxoplasmosis is a ubiquitous protozoan infection caused by coccidian Toxoplasma gondii. In an immunocompetent host, the primary infection is generally oligosymptomatic and self-limiting. Fewer than $10 \%$ of infected subjects are symptomatic, with lymphadenopathy as the most frequent clinical finding. Here, two cases of Toxoplasmic lymphadenitis are reported for otolaryngologists to consider the clinical findings and natural history aspects of this infection.

Korean J Otorhinolaryngol-Head Neck Surg 2015;58(5):341-3

Key Words Cervical lymphadenitis · Parotid - Toxoplasmosis.

\section{Introduction}

Toxoplasmosis is a worldwide parasitic disease. Toxoplasma gondii, a protozoan, causes the infection in humans. ${ }^{1)}$ The clinical manifestations associated with Toxoplasmosis infections are non specific and frequently asymptomatic; they may include low-grade fever, fatigue, and lymphadenopathy. The histopathology and serology are helpful for confirming the diagnosis. Because fewer than $10 \%$ of infected persons are symptomatic, otolaryngologists rarely suspect and diagnose Toxoplasmic lymphadenitis when evaluating patients presenting with mass lesions in the head and neck regions. Several cases of Toxoplasmic lymphadenitis have been reported in the English literature; reports of intraglandular Toxoplasmic lymphadenitis of the parotid gland are extremely rare. ${ }^{1-4)}$ We report Toxoplasmic lymphadenitis of the cervical lymph nodes and the intraglandular lymph nodes of the parotid gland that have been diagnosed retrospectively subsequent to obtaining the results of the postoperative pathology.

\section{Case}

\section{Patient I}

A 34-year-old man presented with an incidentally found painless neck mass present for one month. The patient reported no other constitutional symptoms. Physical examination revealed a firm, round mass at the left cervical level V. Computed tomography localized the $1.5 \mathrm{~cm}$ mass to the posterior cervical triangle (Fig. 1A). There were no remarkable findings in the head and neck region. A fine-needle aspiration biopsy was non-diagnostic. An excisional biopsy was performed for a definitive diagnosis. The pathology examination revealed findings suggestive of Toxoplasmosis.

Toxoplasma serum titers were obtained retrospectively. The 
Toxoplasma immunoglobulin G (IgG) was $164.50 \mathrm{IU} / \mathrm{mL}$ (normal, $<30.00 \mathrm{IU} / \mathrm{mL}$ ), and IgM was $0.64 \mathrm{IU} / \mathrm{mL}$ (normal, $<0.80 \mathrm{IU} / \mathrm{mL}$ ). These results confirmed a previous toxoplasmosis infection (IgG positivity), but not a current infection (IgM negativity). After diagnosing the patient with Toxoplasmic lymphadenitis, the history was repeated retrospectively. The patient was a soldier working in a rural area where many wild cats wandered around his workplace. No treatment was provided. At the 3-month follow-up, the patient remained asymptomatic and no new masses developed in the neck.

\section{Patient 2}

A 40-year-old woman presented with a two-week history of a slowly enlarging mass in the left parotid gland without any other symptoms. The mass was mobile and measured $1.5 \mathrm{~cm}$. There was no facial nerve weakness or twitching noted. Computed tomography localized a mass of the same size to the superficial lobe of the left parotid gland (Fig. 1B). A fineneedle aspiration biopsy was non-diagnostic. A partial parotidectomy was performed, and the findings on histopathology were consistent with Toxoplasmic lymphadenitis (Fig. 2).

Serology for Toxoplasmosis was performed retrospective- ly and a repeat history was performed. The Toxoplasma IgG was $426.10 \mathrm{IU} / \mathrm{mL}$ (normal, $<30.00 \mathrm{IU} / \mathrm{mL}$ ), and the $\mathrm{IgM}$ was $5.66 \mathrm{IU} / \mathrm{mL}$ (normal, $<0.80 \mathrm{IU} / \mathrm{mL}$ ). These results confirmed an acute infection (IgG and IgM positivity) with Toxoplasmosis. The patient lived in a suburban area where wild cats are common around homes. Without treatment, the patient remained asymptomatic and there was no recurrence at the 2-month follow-up.

\section{Discussion}

Toxoplasmosis is a protozoan infection caused by the parasite Toxoplasma gondii. Warm-blooded animals are intermediate hosts, and cats are the definitive hosts. Humans are infected most often through ingestion of cysts in infected and undercooked meat, drinking infected water, or consuming contaminated, unwashed fruits, and vegetables. Clinically, most Toxoplasma seropositive patients are asymptomatic. The most frequently encountered clinical manifestation is posterior cervical lymphadenitis, as was noted in the first case reported here. However, in immunocompromised hosts, a more systemic form can occur, with multiple organ involvement,
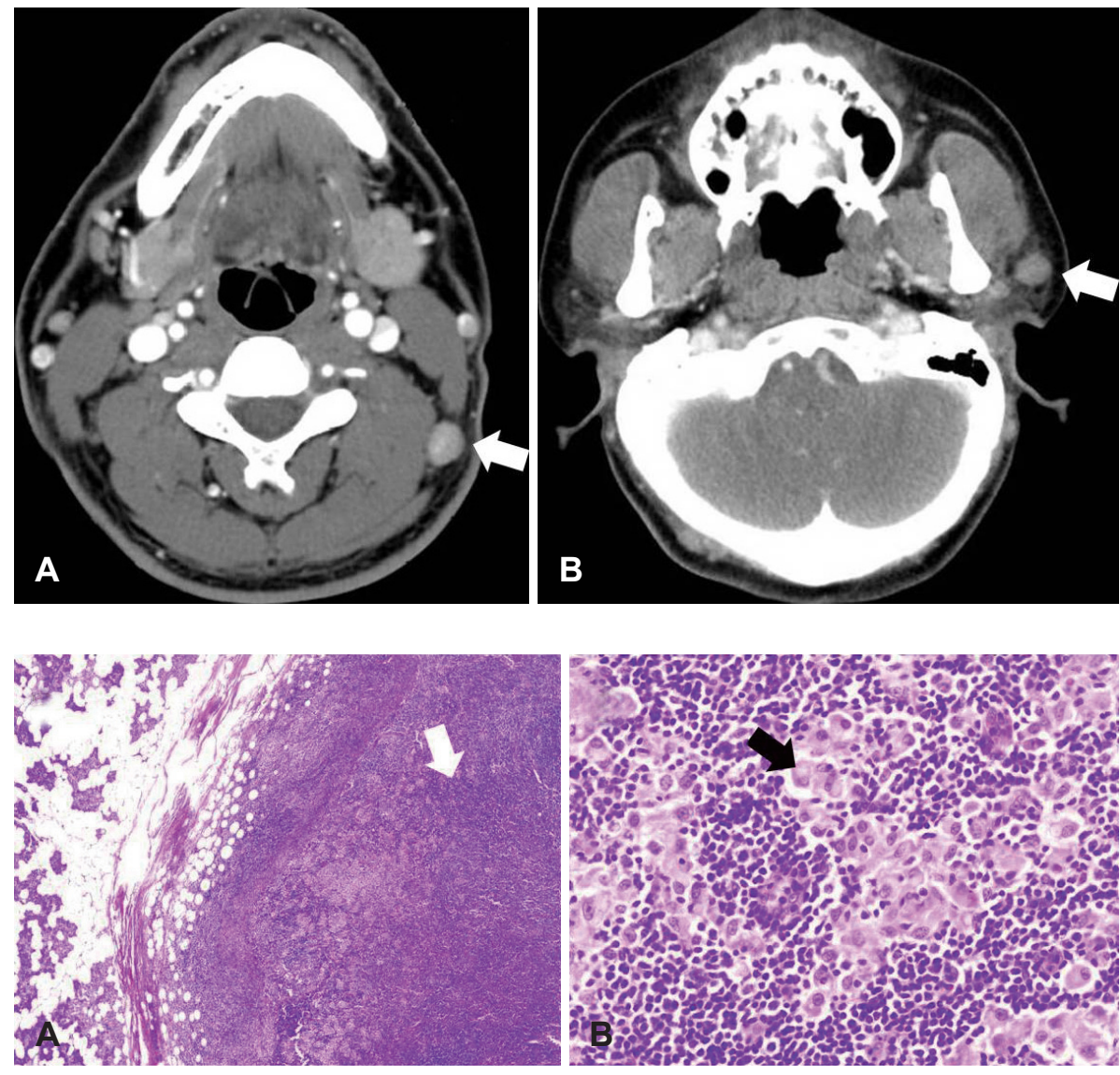

Fig. 2. Histopathological findings of intra-parotid Toxoplasmic lymphadenitis. Low- (A) and high-power (B) views show the preserved lymph node architecture, proliferation of histiocytes, hyperplastic follicles (white arrow), enlarged germinal centers, and epithelioid cells with abundant, pale eosinophilic cytoplasm (black arrow). H-E stain, $\times 100, \times 400$ magnification. 
including the central nervous system, cardiac involvement, pneumonia, and chorioretinitis. ${ }^{5)}$

Serology testing is needed to confirm the diagnosis of toxoplasmosis, in conjunction with the findings on lymph node histology. For the diagnosis of a suspected case of acute toxoplasmosis, IgG and IgM serology are the main clinical tests performed. IgG antibodies become positive two to three weeks after infection, achieve a peak concentration at one to two months later, and remain positive indefinitely. ${ }^{1)}$ On the other hand, IgM antibodies can be detected two weeks after infection, achieve a peak concentration in one month, and decrease thereafter, and usually become undetectable within six to nine months. A single IgM titer of 1:80 or higher is diagnostic; however, a negative result does not rule out an infection. ${ }^{6)}$ In the first case reported here, the serology indicated a previous Toxoplasma infection. The neck mass was an incidental finding; it is unclear when the neck mass first developed. Because the Toxoplasma IgM becomes undetectable within six to nine months, and the Toxoplasma IgM was negative, the neck mass might have developed at least six months ago.

Histologic analysis will reveal that the lymph node architecture is preserved and that hyperplastic follicles are present. Multiple mitoses are seen in the germinal centers. Also present are many epithelioid cells with pale eosinophilic cytoplasm. Histologic triad found in Toxoplasmosis are as follows; 1) lymph node with follicular hyperplasia, 2) clusters of proliferating epithelioid histiocytes, with a mixed lymphocytic and immunoblastic cell population, 3) distension of marginal and cortical sinuses with epithelioid cells.

In general, the clinical course of toxoplasmosis is self-limited. Treatment is unnecessary unless clinical symptoms are severe or persistent, or unless the patient is immunocompromised. However, in some cases where the clinical diagnosis is compromised, persistence of lymphadenopathy would warrant excision or superficial parotidectomy.

In conclusion, two cases of Toxoplasmic lymphadenitis of the head and neck region are reported. Though Toxoplasmic lymphadenitis is relatively rare and intra-parotid Toxoplasmic lymphadenitis is extremely rare, a careful history and examination with appropriate laboratory investigations aid in the confirmation of the diagnosis of this infection.

\section{REFERENCES}

1) Moran WJ, Tom DW, King GD, Silverman ML. Toxoplasmosis lymphadenitis occurring in a parotid gland. Otolaryngol Head Neck Surg 1986;94(2):237-40.

2) Pittam M, Thomas JM. Diseases of the pre-auricular lymph nodes mimicking parotid tumours. Br J Surg 1987;74(12):1172-3.

3) Von Arx DP. Cervicofacial toxoplasmosis. Br J Oral Maxillofac Surg 1988;26(1):70-7.

4) Akiner MN, Saatci MR, Yilmaz O, Erekul S. Intraglandular toxoplasmosis lymphadenitis of the parotid gland. J Laryngol Otol 1991;105(10):860-2.

5) Camacho AE, Goodman ML, Eavey RD. Pathologic correlation of the unknown solid parotid mass in children. Otolaryngol Head Neck Surg 1989;101(5):566-71.

6) Hadi U, Rameh C. Intraglandular toxoplasmosis of the parotid gland pre- or postoperative diagnosis? Am J Otolaryngol 2007;28(3):201-4. 